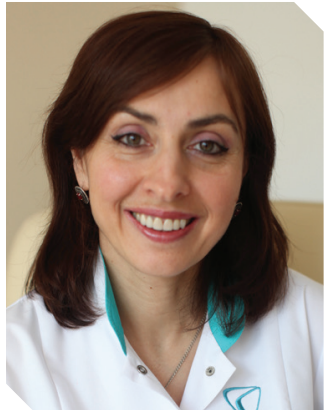

H.B. КОСЕЙ

д. мед. н., главный научный сотрудник отделения эндокринной гинекологии ГУ «Институт педиатрии, акушерства и гинекологии НАМН Украины» ORCID: 0000-0003-3085-3285

\section{С.И. РЕГЕДА}

старший научный сотрудник отделения эндокринной гинекологии ГУ «ИПАГ НАМН Украины»

ORCID: 0000-0002-4960-7175

\section{Н.В. ЯРОЦКАЯ}

младший научный сотрудник отделения эндокринной гинекологии ГУ «ИПАГ НАМН Украины»

ORCID: 0000-0002-0134-920X

\section{A.A. ГОРОХОВА}

врач-интерн отделения эндокринной гинекологии ГУ «ИПАГ НАМН Украины» ORCID: 0000-0002-5820-1687

\section{Контакты:}

Косей Наталья Васильевна ГУ «ИПАГ НАМН Украины», отделение эндокринной гинекологии 04050, Киев, П. Майбороды, 8 тел.: +38 (044) 4838087 ; +38 (050) 4430458 e-mail: nataly.kosey@gmail.com

\title{
СТРЕССОВОЕ БЕСПЛОДИЕ
}

\section{ВВЕДЕНИЕ}

Несмотря на значительные достижения науки и практического здравоохранения, бесплодие остается одной из важнейших медицинских, социальных и государственных проблем: по данным ВО3, с ней сталкивается 15\% супружеских пар репродуктивного возраста во всем мире. В частности, в Украине насчитывается около 20\% бесплодных пар, т.е. каждая пятая семья в стране [1]. Такую ситуацию можно считать чрезвычайной, ведь бесплодие - это не только внутрисемейная проблема, но в первую очередь социальная, ведущая к снижению репродуктивного потенциала и ухудшению демографических показателей страны [1].

Среди причин бесплодия можно выделить как органические, так и функциональные, а также комбинацию факторов. Наиболее частыми из них являются трубный, перитонеальный, эндокринный, маточный, шеечный факторы, а также иммунологические нарушения. Как ни парадоксально, но значительное место среди причин бесплодия занимает так называемое идиопатическое бесплодие, и несмотря на развитие диагностических возможностей, его частота растет.

\section{АНАЛИЗ ЛИТЕРАТУРНЫХ ДАННЫХ И ПОСТАНОВКА ЗАДАЧИ ИССЛЕДОВАНИЯ}

В медицинской практике принято выделять отдельную морфологическую единицу стресс-индуцированное бесплодие, которое на протяжении последних лет приобретает все большую актуальность. На данном этапе его можно отнести к идиопатической форме бесплодия.

Следует также отметить, что способность женщины к зачатию связана не только с состоянием ее репродуктивной системы, но и с ее психоэмоциональным состоянием. В исследованиях, опубликованных журналом Fertility and Sterility в 2005 году, специалисты Калифорнийского Университета в Сан Диего докладывали о том, что стресс может оказывать негативное влияние даже на результаты репродуктивных технологий, включая экстракорпоральное оплодотворение (ЭКО). Однако вопрос стресс-индуцированного бесплодия требует дополнительного изучения с целью выявления перспектив терапии данной патологии для повышения репродуктивных возможностей супружеских пар $[8,9,10]$.

Обращаясь к исторической справке, следует отметить, что термин «стресс» впервые был

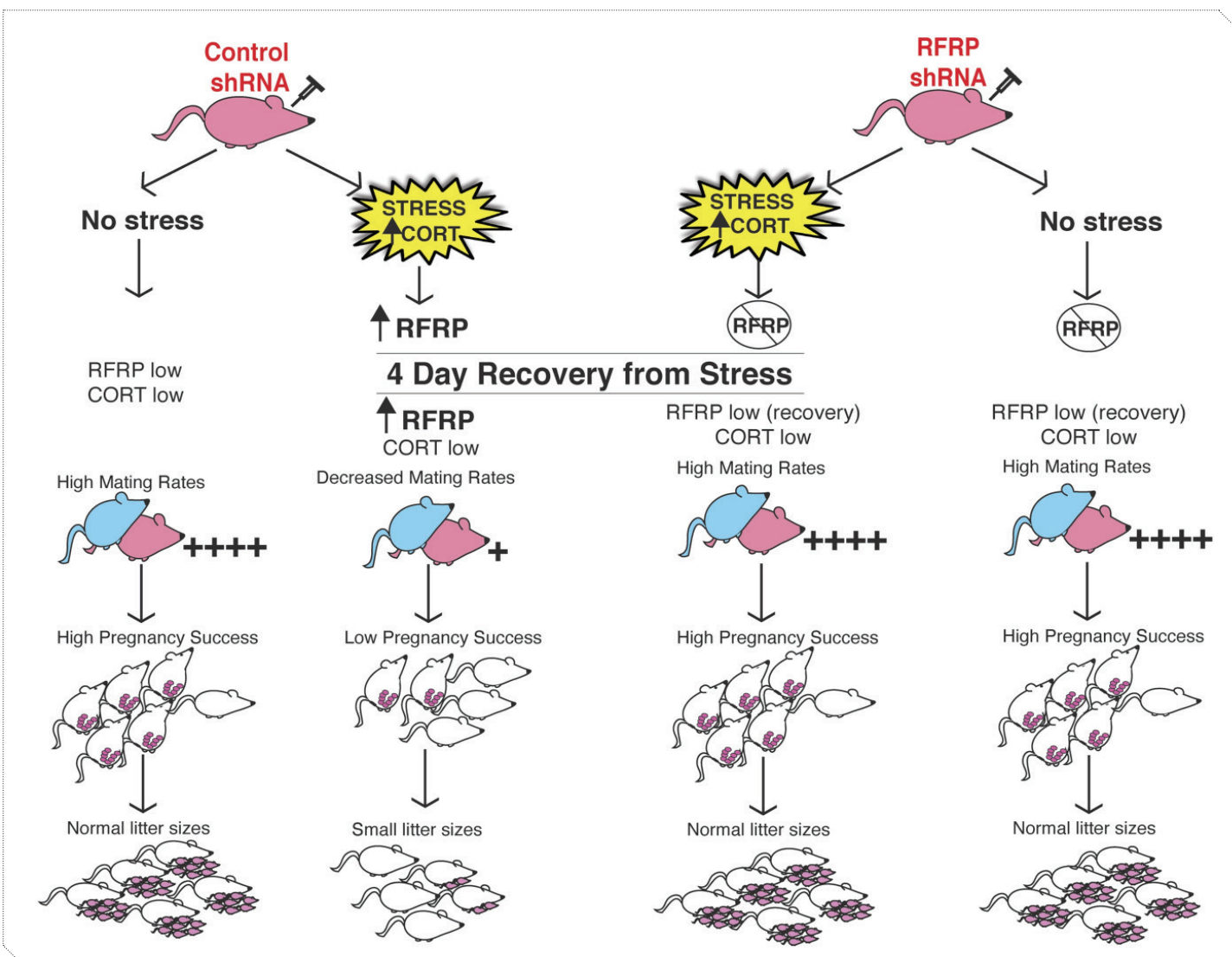

Рисунок 1. Участие RFRP3 в механизме возникновения проблем с фертильностью у самок крыс [7] 
введен английским ученым Робертом Гуком в XVII в. Тогда этот термин был использован для характеристики сопротивления технических объектов испытываемой нагрузке. Данная аналогия помогает понять суть этого процесса, который в современной физиологии и медицине (основываясь на клинических исследованиях Г. Селье) рассматривается как состояние изменения гомеостаза, вызванное внешними или внутренними раздражителями (стрессорами) и проявляется сложной системой физиологических и поведенческих реакций, направленных на поддержание или восстановление оптимального равновесия в организме [11]. В соответствии с этими представлениями стресс рассматривается как физиологический синдром, который состоит из совокупности неспецифически вызванных изменений и является неспецифической реакцией организма на предъявляемые к нему требования [18].

Адаптационная реакция каждого человека на стресс определяется множеством факторов, и изменения в способности эффективно реагировать на раздражители (при чрезмерном и/или длительном воздействии) могут привести к болезни. Кроме того, весьма мощные и/или хронические стрессовые факторы могут оказывать вредное воздействие на различные физиологические функции, в том числе на репродуктивную функцию, метаболизм, состояние иммунной системы, а также на поведение и развитие личности [11].

Основным нейроэндокринным ответом на действие стрессорных агентов и важнейшим механизмом поддержания гомеостаза в организме при стрессе является активация гипоталамо-гипофизарно-надпочечниковой системы с последующей секрецией адренокортикотропного гормона (АКТГ). На повышение уровня АКТГ наиболее быстро реагирует мозговой слой надпочечников, усиливая синтез и выброс катехоламинов (адреналин, норадреналин, дофамин). Адреналин и другие катехоламины оказывают быстрые и мощные эффекты на все сферы жизнедеятельности организма при развитии острой стрессовой реакции. Перестройка базируется на регуляторном изменении функционирования имеющихся внутренних ресурсов $[12,19]$.

Кроме того, АКТГ стимулирует секрецию глюкокортикоидов, повышение уровня которых становится более плавным и растянутым во времени. Кортизол не только обеспечивает адекватную реакцию органов и тканей на хронический стресс, но и адаптирует ткани организма к действию катехоламинов и защищает органы и ткани от воздействия адреналина. Высокий уровень кортизола способствует снижению гонадотропин-рилизинг-гормона (ГнРГ). Параллельно со снижением секреции ГнРГ на фоне влияния глюкокортикоидов происходит повышение уровня гонадотропин-ингибирующего гормона (ГнИГ), что приводит к еще большему снижению секреции ГнРГ, который, как известно, стимулирует синтез, секрецию и высвобождение фолликулостимулирующего (ФСГ) и лютеинизирующего (ЛГ) гормонов. Снижение секреции ФСГ и ЛГ, в свою очередь, может быть причиной нарушения процессов созревания фолликулов, ановуляции, недостаточности лютеиновой фазы, ее укорочения, тем самым уменьшая вероятность успешной имплантации плодного яйца $[12,19]$.
Под действием стрессора также выделяются нейромедиаторы и гормоны: серотонин и мелатонин. Серотонин относится к биогенным аминам и образуется в серотонинергических нейронах, эпифизе, а также энтерохромаффинных клетках ЖКТ. Кроме прямого влияния на овуляцию путем ингибирования ГнРг, повышенный уровень серотонина стимулирует образование пролактина, который наряду с надпочечниковыми гормонами является одним из наиболее активных участников энергетического и пластического обеспечения стресс-реакции: он способен повышать содержание ДНК и РНК, ускорять синтез белка в клетке, повышать активность фосфатаз, увеличивать количество гликогена в клетках, уменьшать потребление глюкозы и кислорода, что обеспечивает адаптацию организма к условиям стресса [12, 18, 24].

Интересен факт открытия гонадотропин-ингибирующего гормона (ГнИГ), обнаруженного впервые 15 лет назад у японской перепелки, который вырабатывается под воздействием стресса и является сильнейшим супрессором фертильности. Его аналог RFRP (RFamide-related peptide), обнаруженный у млекопитающих, а точнее у крыс, мышей и приматов, а также выделенный у людей в 2009 году Джорджем Бэнтли, синтезируется в гипоталамусе и снижает синтез и высвобождение гипофизом гонадотропинов (ЛГ и ФСГ) $[2,34]$.

В частности, у самок крыс RFRP подавляет уровень предовуляционного ЛГ путем ингибирования активации ГнРГ, тогда как у самцов экспрессия RFRP повышается через 24 часа после длительного воздействия стрессора, что позволяет сделать предположение об опосредованном длительном изменении репродуктивной функции [32, 33, 34].

A.C. Geraghty и коллеги [7] экспериментальным путем доказали участие RFRP в механизме возникновения проблем с фертильностью у самок крыс. Исследователи подвергали их стрессу, ограничивая движения самок ежедневно в течение 3 часов на протяжении 18 дней, что спровоцировало повышение у животных уровня гормонов стресса. Далее крысам позволили восстановиться в течение 4 дней (т. е. одного репродуктивного цикла, эквивалентного менструальному циклу у женщин) и обнаружили, что в то время как уровень стрессовых гормонов нормализуется, уровень RFRP в головном мозге остается высоким. Даже после периода восстановления эти самки были менее склонны к спариванию. Интересен тот факт, что у самок, которые были готовы к спариванию, было меньше шансов забеременеть, а те, которым забеременеть удалось, имели больше шансов на потерю эмбрионов. В целом уровень успеха размножения у этих крыс составил только $21 \%$ по сравнению с $76 \%$ в контрольной группе животных, не подвергавшихся воздействию стресса [7].

Далее исследователи вводили в мозг крысам генетически сконструированный вирус, чтобы «выключить» ген, способствующий выработке RFRP в период стресса. Это привело к снижению уровня белка RFRP, и способность спариваться, шансы забеременеть и выживаемость эмбрионов восстановились до нормальных уровней - таких же, как и у крыс, не подвергшихся стрессу. Схематическое изображение экспериментов представлено на рисунке 1. 
Результаты этого исследования свидетельствуют о том, что повышение уровня RFRP во время стресса может иметь серьезные негативные последствия в виде снижения фертильности. В перспективе разработка методов лечения, снижающих уровень RFRP, может способствовать повышению стрессоустойчивости и восстановлению фертильности у женщин со стрессорным бесплодием [32, 34].

Среди причин снижения фертильности значительным оказывается влияние повышенного уровня пролактина. Гиперпролактинемия приводит к ингибированию пульсирующей секреции ГнРГ и снижению частоты импульсов ЛГ, блокаде рецепторов Лг в яичниках, угнетает стимулирующее влияние эстрогенов на секрецию гонадотропинов. Вследствие высокого уровня пролактина происходит ингибирование ФСГ-зависимой овариальной ароматазы, результатом чего становится снижение продукции эстрогенов и ингибирование синтеза прогестерона в клетках гранулезы. Все вышеуказанные процессы приводят к ановуляторному бесплодию [21]. Кроме того, пролактин может быть дополнительным фактором, регулирующим секрецию надпочечниковых андрогенов, поскольку у $40 \%$ больных с гиперпролактинемией имеется нарушение секреции и метаболизма андрогенов - повышение уровней дегидроэпиандростерона и дегидроэпиандростерона сульфата, что приводит к клиническим проявлениям гиперандрогении (гирсутизму и акне) [20, 21].

Молекула пролактина представляет собой полипептид, состоящий из 198 аминокислот. Его синтез и секреция в основном осуществляются лактотрофами, которые составляют от 20 до 50\% всех клеток передней доли гипофиза. Небольшое количество гормона могут секретировать другие отделы мозга, а также молочные железы, Т-лимфоциты, децидуальная оболочка матки и миометрий [19]. Регуляция синтеза и секреции пролактина существенно отличается от других тропных гормонов аденогипофиза и находится под строгим двойным контролем, обусловливающим как стимуляцию, так и подавление (со стороны гипоталамуса посредством нейроэндокринной, аутокринной и паракринной систем) (табл. 1). В настоящее время окончательно установлено, что роль пролактин-ингибирующего фактора выполняет дофамин, синтезирующийся в гипоталамическом тубероинфундибулярном дофаминергическом тракте, нейроны которого расположены в области дугообразного и перивентрикулярного ядер медиобазальной области гипоталамуса. Таким образом, наиболее эффективными в лечении гиперпролактинемии являются агонисты дофамина [21].

Таблица 1. Вещества, регулирующие секрецию пролактина

\begin{tabular}{|c|c|}
\hline Стимулирующие & Ингибирующие \\
\hline Тиролиберин & \\
Серотонин & \\
Вазоактивный интерстициальный пептид (ВИП) & Дофамин \\
Гонадолиберин & Ацетилхолин \\
Эстрогены & ГАМК \\
Прогестерон & Гастрин-рилизинг пептид \\
Опиоидные пептиды & Лей-энкефалин \\
Окситоцин & Соматостатин \\
Ангиотензин II & \\
\hline
\end{tabular}

С целью оптимизации лечения первичного стресс-индуцированного бесплодия была проведена оценка эффективности комплексной терапии, направленной на коррекцию психоэмоционального состояния и вторичной гиперпролактинемии у пациенток с первичным стресс-индуцированным бесплодием.

\section{МАТЕРИАЛЫ И МЕТОДЫ ИССЛЕДОВАНИЯ}

Под нашим наблюдением находились 72 пациентки в возрасте от 24 до 40 лет с репродуктивными планами и первичным стресс-индуцированным бесплодием. В среднем длительность бесплодия у женщин составила 2,7 $\pm 0,5$ года. Были исключены все другие возможные причины неспособности к оплодотворению, и таким образом бесплодие у наблюдаемых было отнесено к идиопатическому. Диагноз был поставлен на основании сбора анамнеза, жалоб, оценки клинических, лабораторных и инструментальных методов исследования, а также результатов психологических тестов. Большинство обследованных пациенток в той или иной степени периодически подвергались стрессу: занимали руководящие должности - 60\% (43 пациентки), имели тяжелую психологическую обстановку на работе - 78\% (56 пациенток) или дома - 24\% (17 пациенток).

Критериями исключения были: тяжелая экстрагенитальная патология, наличие анатомических изменений генитального тракта (лейомиома матки, кисты яичников, полипы эндометрия).

Всем пациенткам назначалась антистрессорная терапия, в состав которой вошли препараты Ноофен (действующее вещество фенибут) и Адаптол (действующее вещество мебикар). Методом рандомизации пациентки были разделены на две группы - основную (I) и группу сравнения (II). В группу I вошли 38 пациенток, которые на фоне антистрессорного лечения получали препарат Циклодинон (специальный экстракт Vitex agnus castus BNO 1095). Группу II составили 34 пациентки, которым была назначена только антистрессорная терапия.

Группы были сопоставимы по возрасту (средний возраст в группе I - 31,7 \pm 2,4 года, в группе II - 30,6 \pm 2,9 года), индексу массы тела (средний показатель в группе I - $22 \pm 3,6$, в группе II - $24 \pm 2,7)$ и длительности бесплодия, которая в среднем составила 2,7 $\pm 0,5$ года у женщин основной группы и 3,2 $\pm 0,7$ года у женщин группы сравнения (во всех случаях $\mathrm{p}>0,05)$.

Комплекс терапии был подобран с учетом характеристик и механизма действия препаратов.

Фенибут - производная ГАМК и фенилэтиламина, применяющаяся в качестве антигипоксанта и антиамнезического средства. Препарат имеет свойства транквилизатора, уменьшает выраженность когнитивных расстройств, проявлений тревожности и страха, нормализует сон, улучшает физическую и умственную работоспособность, имеет свойства антиконвульсанта. У больных с астенией препарат улучшает показатели работоспособности, не вызывая таких побочных эффектов, как возбуждение или раздражительность. Эффективен для лечения больных с вазовегетативными симптомами, такими как головная боль, нарушения сна, частые смены настроения, головокружение. В 
отличие от транквилизаторов, не ухудшает внимание, память и скорость психических реакций.

Мебикар - синтетическое соединение, производное бициклических бисмочевин. Препарат обладает транквилизирующим (анксиолитическим) действием, способствует снижению чувства тревоги, беспокойства, уменьшает раздражительность, обладает мягким седативным действием. Он относится к группе дневных транквилизаторов и не имеет снотворного действия, но потенцирует эффекты препаратов для лечения нарушений сна. Является мембраностабилизатором, церебропротектором и адаптогеном благодаря антиоксидантному эффекту (особенно при стрессе различного генеза, который сопровождается оксидантными явлениями). Имеет свойства антагониста-агониста адренергической системы. Как нейромедиатор он действует дофамин-позитивно, за счет чего наблюдается нормостенический эффект. При длительном его применении отмечается улучшение и нормализация структуры ночного сна, облегчение засыпания, снижение частоты ночных кошмаров. Кроме того, препарат оказывает выраженное ноотропное действие, способствует стабилизации нервной системы при стрессах и умственных нагрузках.

Особого внимания заслуживает фитопрепарат Циклодинон, содержащий специальный экстракт Vitex agnus castus BNO 1095 (стандартизованный по содержанию циклических дитерпенов), который обладает мягким дофаминергическим действием и способствует угнетению секреции пролактина и нормализации функции гипоталамо-гипофизарно-яичниковой системы [14, 15]. Помимо устранения гиперпролактинемии, терапия Циклодиноном приводит к устранению эстроген-прогестеронового равновесия за счет повышения продукции прогестерона во вторую фазу, нормализации циклической секреции гонадотропинов. Кроме того, для данного препарата характерно выраженное антистрессовое действие за счет стимуляции эндорфиновых рецепторов, что особенно ценно для лечения данной категории пациентов. Учитывая, что подавляющее большинство случаев гиперпролактинемии на фоне стресса характеризуются небольшим уровнем повышения концентрации пролактина, чаще функционального характера, именно лекарственные средства мягкого действия являются наиболее оптимальными и в большинстве случаев эффективными $[16,17]$.

Таким образом, пациенткам основной группы были назначены: Ноофен 250 мг 3 раза в сутки на протяжении 1 месяца, Адаптол 300 мг 3 раза в сутки на протяжении 2 месяцев и Циклодинон по 1 таблетке 1 раз в сутки в течение 6 месяцев. Участницы группы сравнения пациенток получали только Ноофен и Адаптол по аналогичной схеме.

Психометрические, клинические, лабораторные, инструментальные методы исследования, а также исследование гормонального гомеостаза проводили до лечения, через 1, 3 и 6 месяцев после начала терапии.

В обеих группах также было проведено тестирование по шкале самооценки уровня тревожности СпилбергераХанина до начала терапии, через 1, 3 и 6 месяцев после ее начала. Предлагаемый тест является надежным и инфор- мативным способом самооценки уровня тревожности в настоящий момент (реактивной тревожности как состояния) и личностной тревожности (как устойчивой характеристики человека). Метод разработан Ч.Д. Спилбергером (США) и адаптирован Ю.Л. Ханиным (Россия) [10]. Реактивная (ситуативная) тревожность (РТ) позволяет оценить состояние человека в текущий момент времени, которое характеризуется субъективно переживаемыми эмоциями: напряжением, беспокойством, озабоченностью, нервозностью в данной конкретной обстановке. Это состояние возникает как эмоциональная реакция на экстремальную или стрессовую ситуацию, может быть разным по интенсивности и динамичным во времени. Личностная тревожность (ЛТ) дает представление о подверженности личности воздействию тех или иных стрессоров вследствие индивидуальных особенностей $[8,10]$.

Тестирование по методике Спилбергера-Ханина проводится с применением двух бланков, раздельно оценивающих РТ и ЛТ (по 20 высказываний в каждом случае) [10]. При интерпретации результат можно оценить следующим образом: до 30 баллов - низкая тревожность; 31-45 - умеренная тревожность; 46 и более баллов - высокая тревожность [10].

Очень высокая тревожность (свыше 46 баллов) может быть прямо связана с наличием невротического конфликта, эмоциональными срывами и психосоматическими заболеваниями. Очень низкая тревожность (менее 12 баллов), наоборот, характеризует состояние как депрессивное, с низким уровнем мотивации. Иногда очень низкая тревожность в показателях теста является результатом активного вытеснения личностью высокой тревоги с целью показать себя «в лучшем свете» [10].

С целью изучения влияния антистрессорной терапии на гормональный гомеостаз нами были изучены концентрации ЛГ, ФСГ, эстрадиола, прогестерона, тестостерона и пролактина в сыворотке крови кубитальной вены до начала лечения, через 1 и 3 месяца после начала антистрессорной терапии. Во избежание колебаний концентрации гормонов в зависимости от фазы менструального цикла (МЦ) у всех пациенток забор крови для определения концентрации Лг, ФСГ, эстрадиола, тестостерона и пролактина в плазме крови проводили в первую фазу МЦ на 5-7 его день, а концентрацию прогестерона в плазме крови - на 19-21 день. Анализы проводились в медицинской лаборатории «Синэво».

Кроме того, проводилось УЗИ органов малого таза на 7-10 день МЦ в динамике до лечения, через 3 и 6 месяцев после начала терапии на аппарате Siemens с использованием вагинального трансдьюсера.

Все показатели сравнивали с соответствующими данными контрольной группы, состоящей из 30 здоровых женщин репродуктивного возраста (средний возраст - 32,2 \pm 2,3 лет).

\section{РЕЗУЛЬТАТЫ ИССЛЕДОВАНИЯ И ИХ ОБСУЖДЕНИЕ}

Анализ полученных результатов показал, что превалирующее большинство женщин до лечения находились в состоянии повышенной РТ, что указывает на выраженное 


\section{РЕПРОДУКТОЛОГІЯ}

действие сильного психоэмоционального стресса у 26 (68,4\%) женщин основной группы и 23 (67,6\%) женщин группы сравнения соответственно (рис. 2).

При оценке Лт было выявлено, что 21 (55,3\%) женщина основной и 21 (61,8\%) женщина группы сравнения также имели высокий уровень личностной тревожности. Это можно объяснить особенностью тревожного психотипа обследуемых женщин, что в свою очередь может способствовать возникновению и прогрессированию стресс-индуцированных соматических заболеваний. Выявленные особенности указывают на то, что именно женщины с эмоционально неустойчивым темпераментом, обусловленным генетической предрасположенностью, в большей степени будут составлять процент пациентов со стресс-индуцированным бесплодием.
Уже через 3 месяца после начала комплексной антистрессорной терапии уровень РТ и в меньшей степени - ЛТ снизился в обеих группах. Так, при проведении тестирования через 1 месяц после начала лечения в I группе в состоянии высокой РТ находилось 9 (23,7\%) женщин, а через 3 месяца их число составило всего 6 (15,8\%), что было достоверно меньше по сравнению с показателями до лечения - 26 (68,4\%) женщин ( $<0,05)$. Bo II группе удельный вес пациенток с высоким уровнем РТ также снизился и составил 17 (31,6\%) женщин через 1 месяц и 9 (26,5\%) женщин через 3 месяца после начала лечения по сравнению с показателем до начала терапии - 23 (67,6\%) женщины.

Средний показатель РТ в основной группе снизился до $38,35 \pm 2,69$ балла через 1 месяц и до 28,14 \pm 1,88 балла через 3 месяца по сравнению с 50,25 \pm 4,11 баллами до лечения $\left(\mathrm{p}_{1-3,2-3}<0,05\right)$ (табл. 2.)

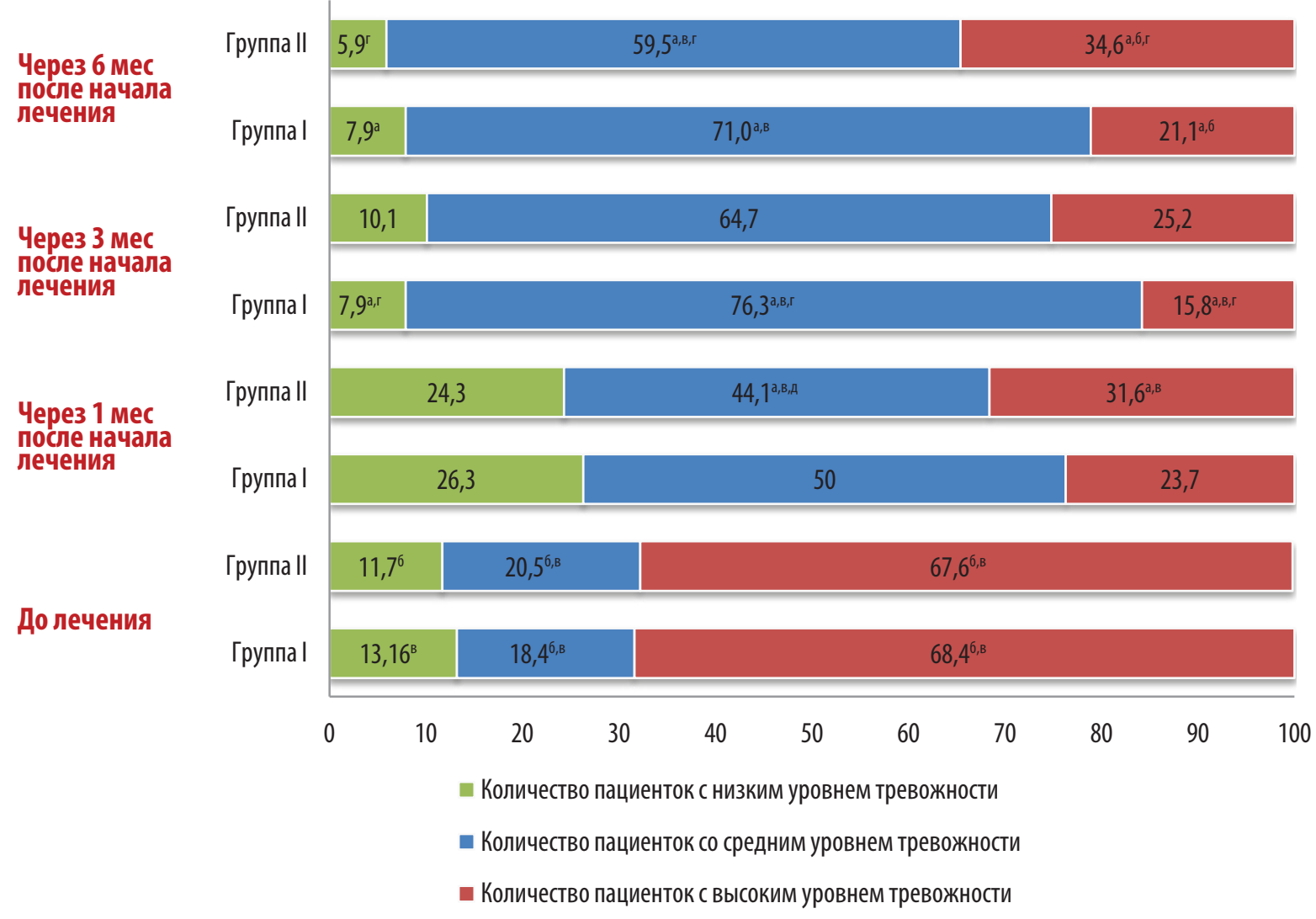

Рисунок 2. Показатели оценки уровня РТ в обследованных группах женщин в динамике лечения, \%

а - разница достоверна относительно показателя до лечения в пределах группы, $\mathrm{p}<0,05$;

${ }^{6}$ - разница достоверна относительно показателя через 1 мес после начала лечения в пределах группы, $\mathrm{p}<0,05$;

в - разница достоверна относительно показателя через 3 мес после начала лечения в пределах группы, $\mathrm{p}<0,05$;

' - разница достоверна относительно показателя в I группе, $\mathrm{p}<0,05$

Таблица 2. Средние показатели РТ в обследуемых группах женщин, баллы

\begin{tabular}{|c|c|c|c|c|c|}
\hline Группы обследуемых & $\mathbf{n}$ & До лечения & Через 1 мес после начала лечения & Через 3 меспосле начала лечения & Через 6 мес после начала лечения \\
\hline Основная группа & 338 & $50,25 \pm 4,11^{6, \mathrm{~B}}$ & $38,35 \pm 2,69^{\mathrm{a}, \mathrm{B}, \mathrm{r}}$ & $28,14 \pm 1,88^{\mathrm{a}, 6}$ & $29,38 \pm 1,54^{\mathrm{a}, 6}$ \\
\hline Группа сравнения & 334 & $49,92 \pm 3,56^{6, \mathrm{~B}}$ & $39,6 \pm 3,17^{\mathrm{a}, \mathrm{B}}$ & $31,27 \pm 2,56^{\mathrm{a}, 6}$ & $35,59 \pm 1,92^{\mathrm{a}}$ \\
\hline
\end{tabular}

а - разница достоверна относительно показателя до лечения в пределах группы, p < 0,05;

6 - разница достоверна относительно показателя через 1 мес после начала лечения в пределах группы, $\mathrm{p}<0,05$;

в - разница достоверна относительно показателя через 3 мес после начала лечения в пределах группы, $p<0,05$;

г - разница достоверна относительно показателя в I группе, p <0,05 
Обращает на себя внимание тот факт, что и через 6 месяцев после начала лечения в основной группе сохранились достигнутые уровни РТ, в то время как во второй группе наблюдалась тенденция к их увеличению.

Показатели ЛТ изменялись в меньшей степени, однако их снижение на фоне проводимого лечения также имело место (рис. 3.)

Для женщин, страдающих стресс-индуцированным бесплодием, характерны изменения гормонального гомеостаза, происходящие под влиянием стрессоров и, как следствие, усиливающие эмоциональные расстройства. Таким образом, формируется «порочный круг» стресс-индуцированных нарушений гормонального фона.

Исследования гормонального гомеостаза у женщин со стресс-индуцированным бесплодием показали снижение среднего уровня гипофизарных гормонов (ЛГ и ФСГ) и достаточно низкие средние концентрации (нижние границы нормы) эстрадиола и прогестерона, что подтверждает нарушение гормонального гомеостаза в виде гипофункции центрального генеза (табл. 4).

В то же время уровень пролактина был умеренно повышен у женщин в обеих исследуемых группах при средних показателях его концентрации 34,47 $\pm 2,84$ и 30,94 \pm 2,47 нг/мл в основной и группе сравнения соответственно. Следует отметить, что у большинства женщин с гиперпролактинемией уровень пролактина был повышен незначительно - до 24-35 нг/мл, и лишь в единичных случаях цифры были выше. Такой уровень гиперпролактинемии указывает на функциональный характер нарушений, в частности на фоне стресса, физического переутомления, нарушения режима сна и бодрствования.

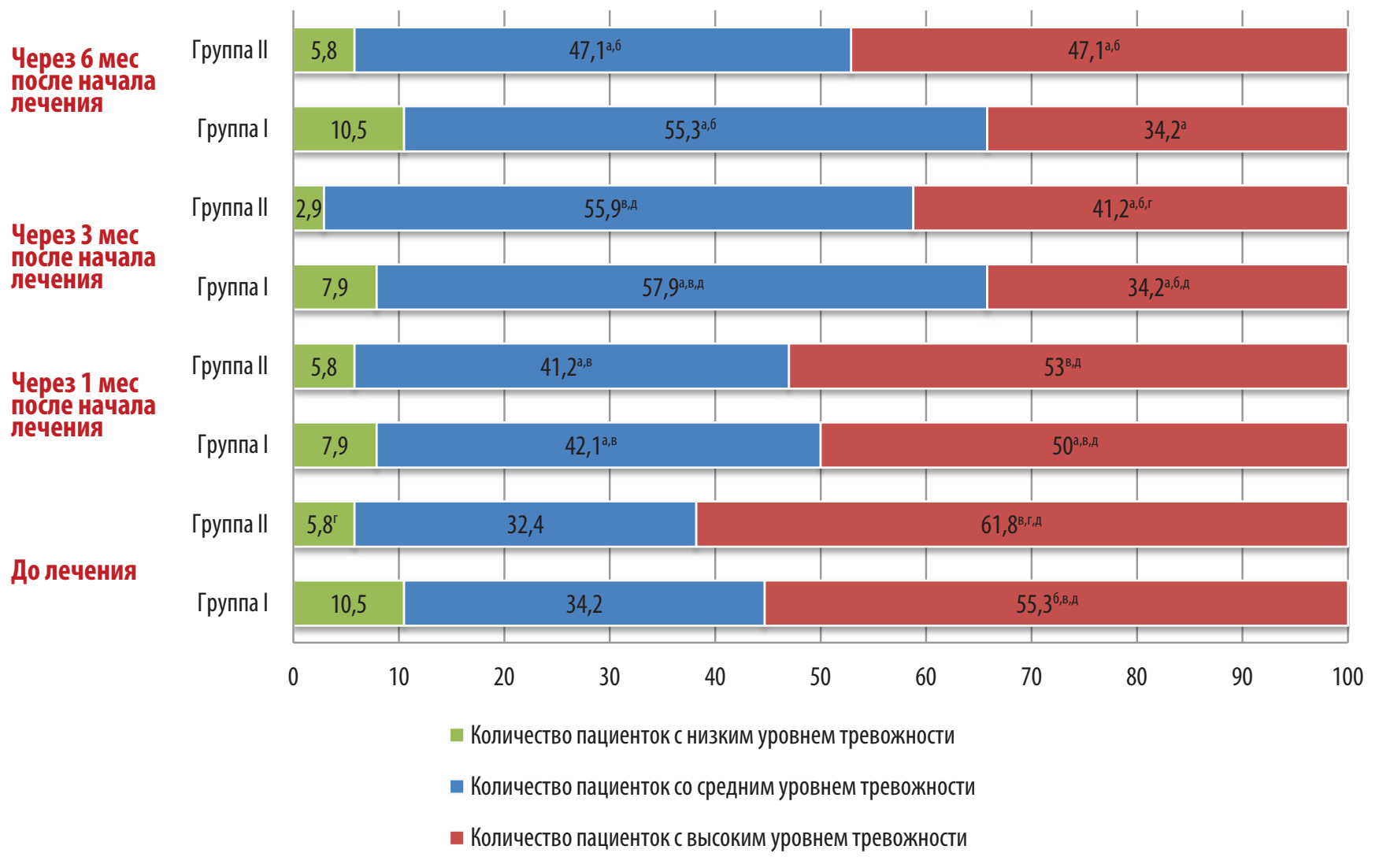

Рисунок 3. Показатели оценки уровня ЛТ в обследованных группах женщин в динамике лечения, \%

а - разница достоверна относительно показателя до лечения в пределах группы, $\mathrm{p}<0,05$;

${ }^{6}$ - разница достоверна относительно показателя через 3 мес после начала лечения в пределах группы, $\mathrm{p}<0,05$;

в - разница достоверна относительно показателя через 6 мес после начала лечения в пределах группы, p < 0,05;

- разница достоверна относительно показателя в І группе, $p<0,05$

\section{Таблица 3. Средние показатели ЛТ в обследуемых группах женщин, баллы}

\begin{tabular}{|c|c|c|c|c|c|}
\hline Группы обследуемых & $\mathbf{n}$ & До лечения & Через 1 меспосле начала лечения & Через 3 меспосле начала лечения & Через 6 меспосле начала лечения \\
\hline Основная группа (I) & 338 & $48,45 \pm 2,13^{в}$ & $47,48 \pm 2,38^{6}$ & $43,1 \pm 1,73^{\text {a }}$ & $38,83 \pm 2,87$ г \\
\hline Группа сравнения (II) & 334 & $49,62 \pm 2,93$ & $46,5 \pm 2,81$ & $42,25 \pm 3,19$ & $40,11 \pm 3,1$ \\
\hline
\end{tabular}

а - разница достоверна относительно показателя до лечения в пределах группы, $\mathrm{p}<0,05$;

${ }^{6}$ - разница достоверна относительно показателя через 1 мес после начала лечения в пределах группы, $\mathrm{p}<0,05$;

в - разница достоверна относительно показателя через 3 мес после начала лечения в пределах группы, $\mathrm{p}<0,05$;

г - разница достоверна относительно показателя группы сравнения, $\mathrm{p}<0,05$ 


\begin{tabular}{|c|c|c|c|c|c|}
\hline \multicolumn{2}{|c|}{ 0бследуемый гормон } & $\mathbf{n}$ & $\begin{array}{c}\text { Средний показатель } \\
\text { концентрации до терапии }\end{array}$ & $\begin{array}{c}\text { Средний показатель } \\
\text { концентрации через } 3 \text { мес }\end{array}$ & $\begin{array}{c}\text { Средний показатель } \\
\text { концентрации через } 6 \text { мес }\end{array}$ \\
\hline \multirow{3}{*}{$\begin{array}{c}\text { Прогестерон, } \\
\text { нг/мл }\end{array}$} & Основная группа & 38 & $7,52 \pm 0,42^{\mathrm{a}, \mathrm{B}}$ & $12,73 \pm 0,95^{6,8}$ & $19,32 \pm 1,61^{a, 6}$ \\
\hline & Группа сравнения & 34 & $9,13 \pm 0,51^{6, r}$ & $11,38 \pm 0,82^{\mathrm{a}}$ & $10,64 \pm 1,34^{\mathrm{B}, \mathrm{r}}$ \\
\hline & Группа здоровых женщин & 30 & \multicolumn{3}{|c|}{$18,29 \pm 1,91$} \\
\hline \multirow{3}{*}{$\begin{array}{l}\text { Эстрадиол, } \\
\text { пг/мл }\end{array}$} & Основная группа & 38 & $57,61 \pm 1,26^{6,8}$ & $93,92 \pm 3,64^{\mathrm{a}, \mathrm{B}}$ & $121,42 \pm 8,39^{\mathrm{a}, 6}$ \\
\hline & Группа сравнения & 34 & $65,78 \pm 1,13^{6, B, \Gamma}$ & $86,41 \pm 3,19^{a, B}$ & $90,52 \pm 7,56^{\mathrm{a}, 6, r}$ \\
\hline & Группа здоровых женщин & 30 & \multicolumn{3}{|c|}{$125,61 \pm 9,3$} \\
\hline \multirow{3}{*}{$\begin{array}{c}\text { Пролактин, } \\
\text { нг/мл }\end{array}$} & Основная группа & 38 & $34,47 \pm 2,84^{6,8}$ & $20,59 \pm 1,97^{\mathrm{a}, \mathrm{B}}$ & $11,48 \pm 0,94^{\mathrm{a}, 6}$ \\
\hline & Группа сравнения & 34 & $30,94 \pm 2,47^{\mathrm{B}}$ & $25,53 \pm 2,06$ & $23,34 \pm 1,62^{2, r}$ \\
\hline & Группа здоровых женщин & 30 & \multicolumn{3}{|c|}{$10,72 \pm 1,02$} \\
\hline \multirow{3}{*}{$\begin{array}{c}\text { ЛГ, } \\
\mathrm{MM0/мл}\end{array}$} & Основная группа & 38 & $4,33 \pm 0,68^{6,8}$ & $6,11 \pm 0,62^{\mathrm{a}}$ & $8,26 \pm 0,74^{\mathrm{a}, 6}$ \\
\hline & Группа сравнения & 34 & $3,82 \pm 0,72$ & $4,93 \pm 0,78$ & $5,11 \pm 0,91$ \\
\hline & Группа здоровых женщин & 30 & \multicolumn{3}{|c|}{$7,72 \pm 0,65$} \\
\hline \multirow{3}{*}{$\begin{array}{c}\text { ФСГ, } \\
\mathrm{MMO/мл}\end{array}$} & Основная группа & 38 & $3,53 \pm 0,34^{\mathrm{B}}$ & $5,30 \pm 0,92^{\mathrm{B}}$ & $7,94 \pm 0,64^{a, 6}$ \\
\hline & Группа сравнения & 34 & $4,14 \pm 0,31$ & $5,22 \pm 0,52$ & $4,82 \pm 0,47$ \\
\hline & Группа здоровых женщин & 30 & \multicolumn{3}{|c|}{$9,72 \pm 0,61$} \\
\hline \multirow{3}{*}{$\begin{array}{l}\text { Тестостерон общий, } \\
\text { нмоль/л }\end{array}$} & Основная группа & 38 & $0,85 \pm 0,04$ & $0,81 \pm 0,03^{8}$ & $0,64 \pm 0,03^{6}$ \\
\hline & Группа сравнения & 34 & $0,88 \pm 0,04^{\mathrm{B}}$ & $0,78 \pm 0,04$ & $0,71 \pm 0,04^{\mathrm{a}}$ \\
\hline & Группа здоровых женщин & 30 & \multicolumn{3}{|c|}{$0,58 \pm 0,02$} \\
\hline
\end{tabular}

а - разница достоверна относительно показателя до лечения в пределах группы, $p<0,05$;

6 - разница достоверна относительно показателя через 3 мес после начала лечения в пределах группы, $p<0,05$;

в - разница достоверна относительно показателя через 6 мес после начала лечения в пределах группы, $p<0,05$;

г - разница достоверна относительно показателя основной группы, $\mathrm{p}<0,05$

Динамический контроль содержания гормонов в сыворотке крови показал существенное снижение средней концентрации пролактина и повышение синтеза ФСГ, ЛГ, эстрадиола и прогестерона на фоне комплексного лечения в основной группе, в то время как в группе сравнения, где применялась только антистрессорная терапия, подобная тенденция наблюдалась, однако полной нормализации не происходило.

Так, у женщин основной группы уже через 3 месяца лечения средняя концентрация пролактина составила 20,59 \pm 1,97 нг/мл, что было существенно ниже показателя до лечения - 34,47 $\pm 2,84$ нг/мл ( $<<0,05)$, и находилась в пределах референтных значений, а по окончании шестимесячного курса лечения снизилась еще больше - до 11,48 土 0,94 нг/мл, что соответствовало рекомендуемым средним значениям. Следует отметить, что ни у одной женщины не было отмечено снижения концентрации пролактина до очень низких (ниже 10 нг/мл) показателей, что бывает при применении сильных препаратов синтетического происхождения. Снижение содержания пролактина сопровождалось постепенной нормализацией стероидопродуцирующей функции яичников, выражавшейся в увеличении средней концентрации эстрадиола с 57,61 \pm 1,26 пг/мл перед началом терапии до 93,92 \pm 3,64 пг/мл через 3 месяца и 121,42 $\pm 8,39$ пг/мл через 6 месяцев терапии $\left(\mathrm{p}_{1-2 ; 2-3}<0,05\right)$, а также росте среднего уровня прогестерона - с 7,52 \pm 0, 42 нг/мл перед началом терапии до 12,73 \pm 0,95 нг/мл через 3 и 19,32 \pm 1,61 нг/мл через 6 месяцев после начала лечения соответственно $\left(\mathrm{p}_{4-5 ; 4-6}<0,05\right)$. Через полгода лечения уровни этих гормонов уже практически не отличались от показателей у здоровых женщин.

В группе сравнения также наблюдалось снижение показателя средней концентрации пролактина, однако и через 3, и через 6 месяцев после начала терапии его средняя концентрация оставалась на верхней границе нормы. Несмотря на некоторое увеличение продукции эстрадиола и прогестерона, которая выражалась в повышении их концентрации в сыворотке крови (эстрадиола с 57,61 \pm 1,26 пг/мл перед лечением до 90,52 \pm 7,56 пг/мл через 6 месяцев тера-

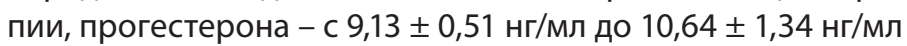
соответственно), уровень стероидных гормонов у женщин группы сравнения все же полностью не восстанавливался и был значительно ниже, чем у здоровых женщин.

В соответствии с изменением баланса гормонального гомеостаза у женщин, страдающих бесплодием, происходят изменения в показателях толщины эндометрия, являющегося мишенью для стероидных гормонов. Нарушения морфофункционального состояния эндометрия наблюдаются у 85\% женщин с гормональной недостаточностью яичников [35]. Проведенные сонографические исследования отобразили показатели толщины эндометрия в основной группе и группе сравнения, которые были существенно меньше таковых у здоровых женщин (табл. 5). При этом они были тем меньшими, чем дольше у женщины не наступала беременность. Была выявлена корреляция $(r=0,68)$ между длительностью стресс-индуцированного бесплодия и толщиной эндометрия. Возможно, это объясняется снижением уровня половых гормонов у 
РЕПРОДУКТОЛОГІЯ

Таблица 5. Средние показатели толщины эндометрия, $\mathrm{M} \pm \mathrm{m}$

\begin{tabular}{|c|c|c|c|c|c|}
\hline Исследуемый показатель & Группы обследуемых женщин & $\mathbf{n}$ & $\begin{array}{c}\text { Средний показатель до } \\
\text { начала лечения }\end{array}$ & $\begin{array}{l}\text { Средний показатель через } 3 \\
\text { мес после начала лечения }\end{array}$ & $\begin{array}{c}\text { Средний показатель через } 6 \\
\text { мес после начала лечения }\end{array}$ \\
\hline \multirow{3}{*}{ Толщина эндометрия, мм } & Основная группа (I) & 38 & $4,74 \pm 0,63^{6,8}$ & $8,12 \pm 0,31^{a}$ & $9,24 \pm 0,8^{\mathrm{a}}$ \\
\hline & Группа сравнения (II) & 34 & $4,25 \pm 0,29^{6, \mathrm{~B}}$ & $6,7 \pm 0,3^{\mathrm{a}, \mathrm{r}}$ & $6,92 \pm 0,55^{\mathrm{a}, \mathrm{r}}$ \\
\hline & Группа здоровых женщин & 30 & & $9,51 \pm 0,68$ & \\
\hline
\end{tabular}

а - разница достоверна относительно показателя до лечения в пределах группы, $\mathrm{p}<0,05$;

${ }^{6}$ - разница достоверна относительно показателя через 3 мес после начала лечения в пределах группы, $p<0,05$;

${ }^{8}$ - разница достоверна относительно показателя через 6 мес после начала лечения в пределах группы, $\mathrm{p}<0,05$;

- разница достоверна относительно показателя основной группы, $p<0,05$

женщин, страдающих стресс-индуцированным бесплодием, и как следствие - нарушением циклической трансформации эндометрия, что приводит к нарушению процессов имплантации плодного яйца.

После проведенной терапии показатели толщины эндометрия увеличились в обеих группах обследуемых женщин. При этом наблюдалось достоверное увеличение ее средних показателей у пациенток, получавших комбинированную терапию: через 6 месяцев лечения средняя толщина эндометрия у них не отличалась от таковой у здоровых женщин. В группе пациенток, получавших лишь антистрессорную терапию, также отмечалось некоторое увеличение средней толщины эндометрия, однако достоверного увеличения отмечено не было, и данный показатель оставался меньшим, чем у здоровых женщин.

Трехлетнее наблюдение за пациентками после курса лечения показало, что в течение первого года беременность наступила у 17 пациенток $(44,7 \%)$ в основной группе, а в течение последующих 3-х лет - еще у 15 женщин (39,4\%), то есть всего забеременели 32 (94,11\%) пациентки основной группы. Среди пациенток группы сравнения беременность в течение первого года наступила лишь у 9 женщин $(26,5 \%)$, а в течение трех лет - еще у 8 (23,5\%), то есть всего в этой группе смогли забеременеть 17 женщин (50\%).

\section{ВЫводы}

Учитывая все полученные данные, можно сделать вывод, что комплексная антистрессорная терапия, стабилизируя психоэмоциональное состояние женщины, способствует восстановлению гормонального гомеостаза и функционального состояния толщины эндометрия, которые влияют на шансы имплантации плодного яйца.

Проведенные исследования показали высокую эффективность комбинации антистрессорной и дофаминергической терапии в лечении стресс-индуцированного бесплодия. Стабилизация психоэмоционального состояния и снижение уровня тревожности способствует нормализации гормонального гомеостаза (умеренному снижению уровня пролактина и активизации гипофизозависимой стероидпродуцирующей функции яичников), а также улучшению функционального состояния эндометрия, зависящего от влияния эстрогенов и прогестерона и влияющего на вероятность имплантации плодного яйца.

С учетом всего вышеперечисленного можно рекомендовать назначение дофаминергических фитопрепаратов, в частности, Циклодинона, на фоне антистрессорной терапии пациенткам со стресс-индуцированным бесплодием с целью коррекции психосоматических нарушений и повышения клинической частоты беременности.

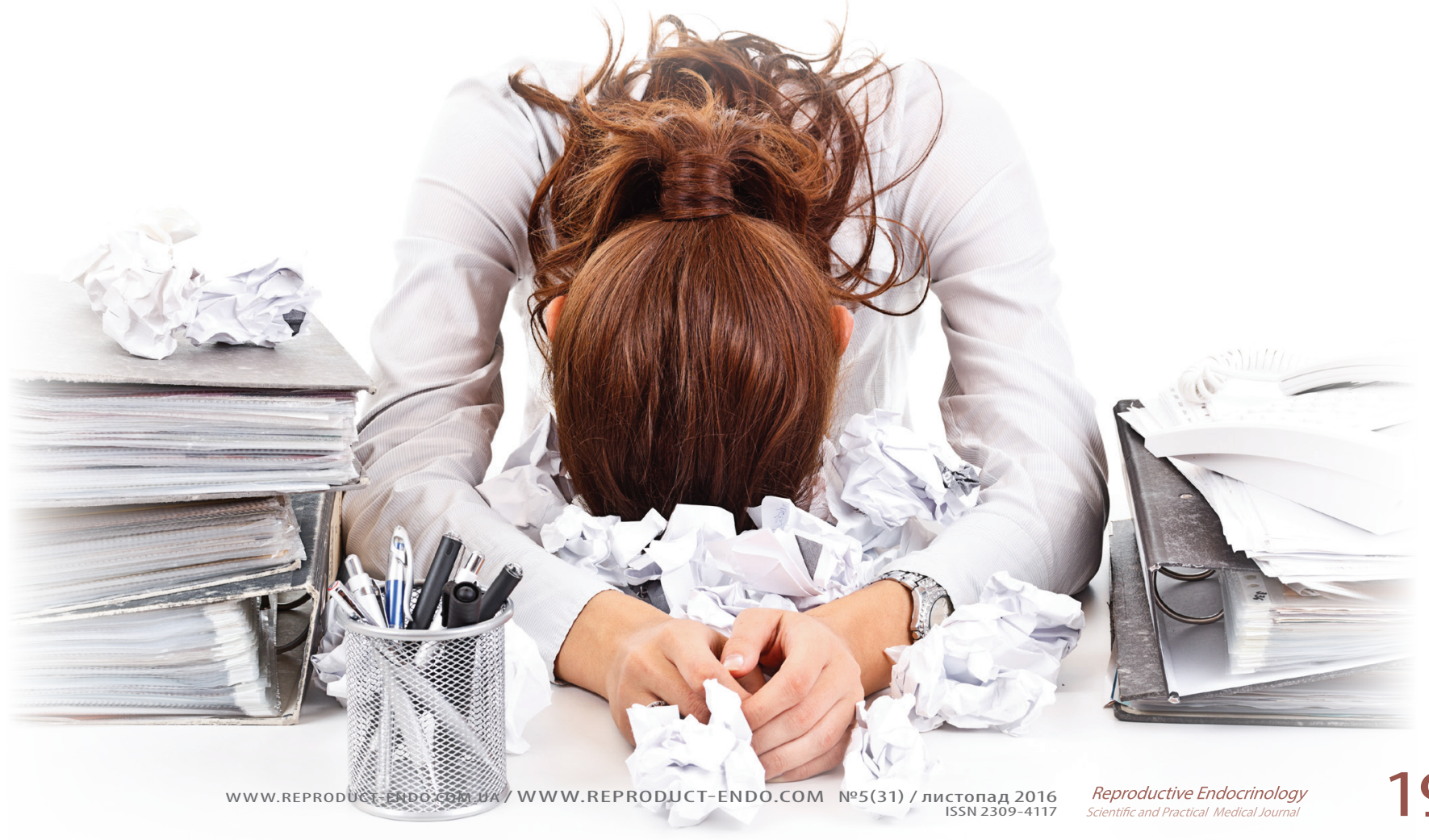




\section{РЕПРОДУКТОЛОГІЯ}

\section{ЛИТЕРАTУPA/REFERENCES}

1. Паращук, Ю.С.

Безплідність у шлюбі : навч. посібник / Ю.С. Паращук,

0.І. Каліновська, М.Г. Грищенко, В.Ю. Паращук. - Харків: ХНМУ. - 2014. - 124 c.

Parashchuk, Y.S., Kalinovska, A.I., Gryshchenko, M.G., Parashchuk, V.Y.

Infertility in marriage: tutorial. Kharkiv. KhNMU (2014): 124 p.

2. Louis, G.M., Lum, K.J., Sundaram, R., et al.

"Stress reduces conception probabilities across the fertile window: evidence in support of relaxation." Fertil Steril 95 (2011): 2184-9.

3. Piekarski, D.J., Zhao, S., Jennings, K.J., et al.

"Gonadotropin-inhibitory hormone reduces sexual motivation but not lordosis behavior in female Syrian hamsters (Mesocricetus auratus)." Hormones and Behavior 64 (2013): 501-10.

4. Sanders, $R$.

«Blocking hormone could eliminate stress-induced infertility». Berkeley news online, Jan 12, 2015. Available from: [http:// news.berkeley.edu/2015/01/12/blocking-hormone-couldeliminate-stress-induced-infertility/], last accessed Nov 15, 2016.

5. Sato, Y., Suzuki, N., Horita, H., et al.

"Effects of long-term psychological stress on sexual behavior and brain catecholamine levels." Journal of Andrology 17 (1996): $83-90$.

\section{Son, Y.L., Ubuka, T., Millar, R.P., et al.}

«Gonadotropin-inhibitory hormone inhibits GnRH-induced gonadotropin subunit gene transcriptions by inhibiting $\mathrm{AC/}$ cAMP/PKA-dependent ERK Pathway in L[beta]T2 cells." Endocrinology 153 (2012): 2332-43.

7. Anna C. Geraghty, Sandra E. Muroy, Sheng Zhao, et al. Knockdown of hypothalamic RFRP3 prevents chronic stress-induced infertility and embryo resorption. University of California. Berkeley, United States. Canadian Institute for Advanced Research, Canada.

8. Батаршев, А.B.

Базовые психологические свойства и самоопределение личности: Практическое руководство по психологической диагностике. - СПб:: Издательство «Речь». - 2005. - С. 44-49. Batarshev, A.V.

Basic psychological characteristics and self-identity: A Practical Guide for psychological diagnostics. St.-Petersburg. Publishing house "Rech" (2005): 44-49.

9. Диагностики эмоционально-нравственного развития / Ред. и сост. И.Б. Дерманова. - СПб.: Издательство «Речь». 2002. - C. 124-126.

The diagnostics of emotional and moral development.

Ed. by I.B. Dermanova. St.-Petersburg. Publishing house "Rech" (2002): 124-6.

10. Практикум по психологии состояний: Учебное пособие / Под ред. проф. О.А. Прохорова. - СПб: Издательство «Речь». - 2004. - C. 121-122.

Practical for Psychology states: Textbook.

Ed. by prof. 0.A. Prokhorov. St.-Petersburg. Publishing house "Rech" (2004): 121-2.

11. Селье, Г.

Очерки 06 адаптационном синдроме. - М.: Медгиз. - 1960. Selye, $\mathrm{H}$.

Essays about adaptation syndrome. Moscow. Medgiz (1960).

12. Морозов, В.H.

К современной трактовке механизмов стресса / В.Н.

Морозов, А.А. Хадарцев // ВНМТ. - 2010. - № 1.

Morozov, V.N., Khadartsev, A.A.

"To the modern interpretation of stress mechanisms." VNMT 1 (2010).
13. Paton, A., Harley, R., Harvey, T.

"Editorial."Vitex: A Newsletter for Lamiaceae \& Verbenaceae Research 1 (2000), available from: [http://www.kew.org/data/ vitex/jan00.pdf], last accessed Nov 15, 2016.

14. Merz, P.G., Gorkow, C., Schrödter, A., et al.

"The effects of a special Agnus castus extract (BP1095E1) on prolactin secretion in healthy male subjects." Exp Clin Endocrinol Diabetes 104.6 (1996): 447-53.

15. Berger, D., Schaffner, W., Schrader, E., et al. "Efficacy of Vitex agnus castus L. extract Ze 440 in patients with pre-menstrual syndrome (PMS)". Arch Gynecol Obstet 264.3 (2000): 150-3.

16. Schellenberg, $R$.

"Treatment for the premenstrual syndrome with agnus castus fruit extract: prospective, randomised, placebo controlled study." British Medical Journal 322.7279 (2001): 134-7.

17. Milewicz, A., Gejdel, E., Sworen, H., et al.

"Vitex agnus castus extract in the treatment of luteal phase defects due to latent hyperprolactinemia. Results of a randomized placebo-controlled double-blind study." Arzneimittelforschung 43.7 (1993): 752-6.

18. Дмитриева, Т.Б., Дроздов, А.З., Коган, Б.М. Основные неспецифические системы, адаптирующие организм к острому и хроническому стрессу. Психиатрия чрезвычайных ситуаций. Руководство - М.: 2004. - С. 8-41. Dmitrieva, T.B., Drozdov, A.Z., Kogan, B.M.

Main non-specific systems, which are adapting organism to acute and chronic stresses. Psychiatry of emergency situations. Guideline. Moscow (2004): 8-41.

19. Балаболкин, М. И.

Эндокринология / М.И. Балаболкин. - М.: Медицина. 1989. -416 c.

Balabolkin, M.I.

Endocrinology. Moscow. Medicine (1989): 416 p.

20. Вакс, В.В.

Гиперпролактинемия: причины, клиника, диагностика и лечение / В.B. Вакс // Consilium medicum. - 2001. - Т. 3, № 11. - C. 516-525.

Vaks, V.V.

"Hyperprolactinemia: causes, clinical features, diagnosis and treatment." Consilium medicum 3.11 (2001): 516-25.

21. Дзеранова, Л.К.

Макропролактинемия / Л.К. Дзеранова, К.И. Табеева, Н.П.

Гончаров и др. // Проблемы репродукции. - 2005. - №

11(2). - C. 60-65.

Dzeranova, L.K., Tabeeva, K.I., Goncharov, N.P., et al.

"Macroprolactinemia." Problems of reproduction 11.2 (2005):

60-5.

22. Colao, A., di Sarno, A., Pivonello, R., et al.

"Dopamine receptor agonists for treating prolactinomas." Expert Opin Investig Drugs 11.6 (2002): 787-800.

23. Delitala, $G$.

Hyperprolactinaemia: causes, biochemical diagnosis and tests of prolactin secretion. Clinical Endocrinology ed. by A. Grossman. Oxford (1992): 123-47.

24. Molitch, M.E.

"Disorders of prolactin secretion." Endocrinol Metab Clin North Am 30.3 (2001): 585-610.

25. Olukoga, A.0.

"Macroprolactinaemia is clinically important." J Clin Endocrinol Metab 87.10 (2002): 4833-4.

26. Schlechte, J.A.

"Editoral: the macroprolactin problem."J Clin Endocrinol Metab 87.12 (2002): 5408-9.
27. Toldy, E., Zoltan, L., Szabolcs, I.

"Hyperprolactinemia." Endocrine 22.3 (2003): 267-73.

28. Акмаев, И.Г.

Нейроиммуноэндокринология: истоки и перспективы развития / И.Г. Акмаев //Усп. физиол. наук. - 2003. Т. 34, № 4. - С. 4-15.

\section{Akmaev, I.G.}

"Neuroimmunoendocrinology: origins and prospects of development." Advances of Physiological Sciences 34.4 (2003): 4-15.

29. Шаляпина, В.Г.

Реактивность гипофизарно-адренокортикальной системы на стресс у крыс с активной и пассивной стратегиями поведения / В.Г. Шаляпина, В.В. Ракицкая // Рос. физиол.

журн. им. И.М. Сеченова. - 2003. - Т. 89, № 5. - С. 585-590.

Shaliapina, V.G., Rakitskaya, V.V.

"The reactivity of the pituitary-adrenocortical system to stress in rats with active and passive strategies of behavior." I.M. Sechenov Russ. Physiol. Journ. 89.5 (2003): 585-90.

30. Aguilera, G., Kiss, A., Liu, Y., Kamitakahara, A. Stress 10.2 (2007): P. 153-61.

31. Ben-Jonathan, N., Liby, K., McFarland, M., Zinger, M. "Prolactin as an autocrine/paracrine growth factor in human cancer." Trends Endocrinol Metab 13.6 (2002): 245-50.

32. Hinuma, S., Shintani, Y., Fukusumi, S., et al. "New neuropeptides containing carboxy-terminal RFamide and their receptor in mammals." Nat Cell Biol 2.10 (2000): 703-8.

33. Tsutsui, K., Saigoh, E., Ukena, K., et al.

"A novel avian hypothalamic peptide inhibiting gonadotropin release." Biochem Biophys Res Commun 275.2 (2000): 661-7.

34. Yin, H., Ukena, K., Ubuka, T., Tsutsui, K.

"A novel G protein-coupled receptor for gonadotropininhibitory hormone in the Japanese quail (Coturnix japonica): identification, expression and binding activity."J Endocrinol 184.1 (2005): 257-66.

35. Серов B.H.

Диагностика гинекологических заболеваний с курсом патологической анатомии / В.Н. Серов,

И.Н. Звенигородский. - М.: БИНОМ. Лаборатория знаний. $-2003 .-139$ c.

Serov, V.N., Zvenigorodskiy, I.N.

Diagnosis of gynecological diseases with a course of pathological anatomy. Moscow. BINOM. Knowledge Laboratory (2003): 139 p. [P 


\section{СТРЕССОВОЕ БЕСПЛОДИЕ}

Н.В. Косей, д. мед. н., гл. науч. сотрудник отделения эндокринной гинекологии ГУ «ИПАГ НАМН Украины»

С.И. Регеда, ст. науч. сотрудник отделения эндокринной гинекологии ГУ «ИПАГ НАМН Украины»

Н.В. Яроцкая, мл. науч. сотрудник отделения эндокринной гинекологии ГУ «ИПАГ НАМН Украины»

А.А. Горохова, врач-интерн отделения эндокринной гинекологии ГУ «И ПАГ НАМН Украины»

С целью оптимизации лечения первичного стресс-индуцированного бесплодия авторы статьи провели оценку эффективности комплексной терапии, направленной на коррекцию психоэмоционального состояния и вторичной гиперпролактинемии у 72 пациенток в возрасте от 24 до 40 лет с репродуктивными планами (38 женщин основной группы и 34 - группы сравнения). Контрольную группу составили 30 здоровых женщин.

Исследования гормонального гомеостаза пациенток до лечения показали снижение среднего уровня гипофизарных гормонов, достаточно низкие средние концентрации эстрадиола и прогестерона, умеренно повышенный уровень пролактина и сниженные показатели толщины эндометрия. Превалирующее большинство женщин находилось в состоянии повышенной реактивной и личностной тревожности.

Всем участницам исследования назначалась антистрессорная терапия (фенибут + мебикар). Кроме того, пациентки основной группы на фоне антистрессорного лечения получали препарат Циклодинон, который обладает мягким дофаминергическим действием, способствуя угнетению секреции пролактина и нормализации функции гипоталамогипофизарно-яичниковой системы.

Уже через 3 месяца после начала комплексной антистрессорной терапии в обеих группах снизился уровень реактивной тревожности, и в меньшей степени личностной тревожности. Динамический контроль содержания гормонов показал существенное снижение средней концентрации пролактина и повышение синтеза фолликулостимулирующего, лютеинизирующего гормонов, эстрадиола и прогестерона в сыворотке крови женщин группы приема Циклодинона, где также достоверно снизилась средняя концентрация пролактина и увеличилась толщина эндометрия. В группе сравнения, где применялась только антистрессорная терапия, подобная тенденция наблюдалась, однако полной нормализации не произошло.

В течение трех лет после курса лечения беременность наступила у 32 (94,11\%) пациенток основной группы, и лишь у 17 (50\%) - группы сравнения.

Из результатов исследования можно сделать вывод о высокой эффективности комбинации антистрессорной и дофаминергической терапии. Следовательно, можно рекомендовать назначение дофаминергических фитопрепаратов, в частности, Циклодинона, на фоне антистрессорной терапии пациенткам со стресс-индуцированным бесплодием с целью коррекции психосоматических нарушений и повышения клинической частоты беременности.

Ключевые слова: стресс, бесплодие, тревожность, Циклодинон.

\section{СТРЕСОВЕ БЕЗПЛІДДЯ}

Н.В. Косей, д. мед. н., гол. наук. співробітник відділення ендокринної гінекології ДУ «ІПАГ НАМН України»

С.І. Регеда, ст. наук. співробітник відділення ендокринної гінекології ДУ «ППАГ НАМН України»

Н.В.Яроцька, мол. наук. співробітник відділення ендокринної гінекології ДУ «ІПАГ НАМН України»

Г.0. Горохова, лікар-інтерн відділення ендокринної гінекології ДУ «І ПАГ НАМН України»

3 метою оптимізації лікування первинного стрес-індукованого безпліддя автори статті провели оцінку ефективності комплексної терапії, спрямованої на корекцію психоемоційного стану та вторинної гіперпролактинемії у 72 пацієнток віком від 24 до 40 років з репродуктивними планами (38 жінок основної групи і 34 - групи порівняння). Контрольну групу склали 30 здорових жінок.

Дослідження гормонального гомеостазу пацієнток до лікування показали зниження середнього рівня гіпофізарних гормонів, досить низькі середні концентрації естрадіолу і прогестерону, помірно підвищений рівень пролактину і знижені показники товщини ендометрія. Переважна більшість жінок перебувала в стані підвищеної реактивної й особистісної тривожності.

Всім учасницям дослідження призначалася антистресова терапія (фенібут + мебікар). Крім того, пацієнтки основної групи на тлі антистресорного лікування отримували препарат Циклодинон, який має м'яку дофамінергічну дію, сприяючи пригніченню секреції пролактину і нормалізації функції гіпоталамо-гіпофізарно-яєчникової системи.

Вже через 3 місяці після початку комплексної антистресорної терапії в обох групах знизився рівень реактивної тривожності, і меншою мірою - особистісної тривожності. Динамічний контроль вмісту гормонів показав істотне зниження середньої концентрації пролактину та підвищення синтезу фолікулостимулюючого, лютеїнізуючого гормонів, естрадіолу і прогестерону в сироватці крові жінок групи прийому Циклодинону, де також достовірно знизилася середня концентрація пролактину і збільшилася товщина ендометрія. В групі порівняння, де застосовувалася тільки антистресорна терапія, подібна тенденція спостерігалася, однак повної нормалізації не відбулося.

Протягом трьох років після курсу лікування вагітність настала у 32 (94,11\%) пацієнток основної групи, і лише у 17 (50\%) - групи порівняння.

І результатів дослідження можна зробити висновок про високу ефективність комбінації антистресорної та дофамінергічної терапії. Отже, можна рекомендувати призначення дофамінергічних фітопрепаратів, зокрема, Циклодинону, на тлі антистресорної терапії пацієнткам зі стрес-індукованим безпліддям з метою корекції психосоматичних порушень і підвищення клінічної частоти вагітності.

Ключові слова: стрес, безпліддя, тривожність, Циклодинон.

\section{STRESS INFERTILITY}

N.V. Kosei, MD, chief researcher at the Endocrine Gynecology Department, SI "Institute of Pediatrics, Obstetrics and Gynecology of the NAMS of Ukraine" S.I. Reheda, senior researcher at the Endocrine Gynecology Department, SI "Institute of Pediatrics, Obstetrics and Gynecology of the NAMS of Ukraine" N.V. larotska, junior researcher at the Endocrine Gynecology Department, SI "Institute of Pediatrics, Obstetrics and Gynecology of the NAMS of Ukraine" G.0. Gorokhova, doctor-intern at the Endocrine Gynecology Department, SI "Institute of Pediatrics, Obstetrics and Gynecology of the NAMS of Ukraine"

In order to optimize the treatment of the primary stress-induced infertility the authors evaluated the effectiveness of complex therapy aimed at correcting the mental and emotional state, and the secondary hyperprolactinemia in 72 patients aged 24 to 40 years old with reproductive plans ( 38 women from the main group and 34 - the comparison group). The control group consisted of 30 healthy women.

Research of hormonal homeostasis of patients before treatment was showed a decrease in the average level of the pituitary hormones, low average concentrations of estradiol and progesterone, moderately elevated level of prolactin, and reduced indicators of endometrial thickness. The vast majority of women were in a heightened state of reactive and personal anxiety.

All of study participants received anti-stress therapy (phenibut + mebicar). In addition, the main group on the background of anti-stress treatment received the drug Cyclodynon, which has a mild dopaminergic action, contributing to inhibition of prolactin secretion and normalize the function of the hypothalamic-pituitary-ovarian system.

Within 3 months after the start of a complex anti-stress therapy in both groups the level of reactive anxiety was reduced, and the level of personal anxiety was reduced a lesser extent. Dynamic control of hormones showed a significant decrease in the average concentrations of prolactin and increase of the synthesis of follicle-stimulating, luteinizing hormone, estradiol and progesterone in the blood serum of a group of women receiving Cyclodynon. In that group also was observed a significantly reduction the average concentration of prolactin and increased endometrial thickness. In the comparison group, which applied only anti-stress therapy, a similar trend was observed, but the full normalization not happened.

Within three years after treatment the pregnancy occurred in 32 (94.11\%) women of the main group, and only 17 (50\%) - of the comparison group.

The conclusion of research results: the combination of anti-stress and dopaminergic therapies is very effective. Consequently, it is possible to recommend assignment dopaminergic phytodrugs (in particular Cyclodynon) on background of anti-stress therapy for patients with stress-induced infertility with a view to correction of psychosomatic disorders and improvement of clinical pregnancy rates.

Keywords: stress, infertility, anxiety, Cyclodynon. 